\title{
Abordagem sistêmica do design na contação de histórias com vistas à sustentabilidade cultural de Itamatatiua
}

Systemic design approach in storytelling with a view to the cultural sustainability of Itamatatiua

CESTARI, Glauba Alves do Vale; Doutoranda; Universidade Federal de Santa Catarina - NAS Design

glauba.cestari@ifma.edu.br

FIGUEIREDO, Luiz Fernando Gonçalves de; Pós-doutor; Universidade Federal de Santa Catarina - NAS Design

Iffigueiredo2009@gmail.com

\section{Resumo}

O quilombo de Itamatatiua (MA) a mais de 300 anos resiste e luta pela manutenção de sua cultura associada às práticas herdadas. Porém, hoje, as ceramistas quilombolas, responsáveis pela transferência dos saberes e fazeres que identificam a cultura desse povoado, convivem com o distanciamento das novas gerações. Esse fato consiste, entre outros, em um grave problema que induz à possíveis impactos à sustentabilidade cultural local. Acredita-se que o resgate e inovação da contação de histórias entre gerações, forma de transferência de experiências, pode favorecer a continuidade da intergeracionalidade. Este estudo trata sobre contação de histórias, mediante pesquisa qualitativa participativa, apoiada na abordagem sistêmica do design. A relevância desse artigo está em refletir sobre novas formas de abordagem sistêmica no design com vistas à transferência de experiências para sustentabilidade cultural de Itamatatiua.

Palavras-chave: design; sustentabilidade; contação de histórias; quilombo.

\begin{abstract}
The Itamatatiua quilombo for over 300 years resists and strives to maintain its culture associated with inherited practices. Today, however, the quilombola potters, who are responsible for transferring the knowledge and practices that identify the culture of this village, live with the distance of the new generations. This fact is, among others, a serious problem that leads to possible impacts on local cultural sustainability. It is believed that the rescue and innovation of intergenerational storytelling, a way of transferring experiences, can favor the continuity of intergenerationality. This study deals with storytelling, through participatory qualitative research, supported by a systemic approach to design. The relevance of this article is to reflect on new forms of systemic approach in design with a view to transferring experiences to Itamatatiua's cultural sustainability.
\end{abstract}

Keywords: design; sustainability; storytelling; quilombo. 


\section{Introdução}

O quilombo de Itamatatiua é conhecido pela produção de artefatos em cerâmica, em especial, o pote de cerâmica. Esse povoado que está localizado no município de Alcântara ${ }^{1}$, ao norte do Estado do Maranhão, segue resistindo e lutando pela manutenção de sua cultura em um contexto no qual tradição e inovação convivem em um mesmo espaço e tempo mediante a presença de "outros" (turistas, pesquisadores, membros representantes de entidades públicas, ONGs, etc.). Ainda que por pouco tempo, esses atores interagem com os quilombolas e têm acesso às práticas advindas dos conhecimentos dos seus ancestrais, modos de fazer e viver desse povo que foram transmitidos como herança por um processo de intergeracionalidade (CESTARI, 2014).

Ao se tratar de conhecimentos ou experiências vividas, o quilombo de hoje não se limita a transmissão oral dos chamados "antigos" para os "novos", embora essa prática seja essencial à preservação da cultura herdada. A escola também contribui para a educação. Porém, mesmo diante da existência de políticas governamentais integradas ao Programa Brasil Quilombola ${ }^{2}$ que visa a assistência às comunidades tradicionais, os alunos lidam com carências na infraestrutura da escola, conteúdo didático desconectado da cultura afrodescendente, falta de materiais e tecnologias contemporâneas e também ausência de professores. Com base em Reis (2010), são fatos comuns à muitas comunidades remanescentes da histórica formação dos quilombos no País.

A problemática conduz ao risco da ruptura da transmissão de experiências passadas de geração à geração. O distanciamento da cultura de seus ancestrais ocorre de várias formas, entre essas, pode-se citar o conteúdo introduzido nas escolas disponíveis às comunidades e também à presença do "outro", portador de diferentes conhecimentos, modos de produzir e viver. Nesse contexto inserem-se turistas e agentes de pesquisa e fomento das produções desenvolvidas nessas localidades resultando em interlocuções e interações. No contexto dos agrupamentos quilombolas, as interações entre culturas podem ser positivas por um lado, pois gera uma rede de interesses nas comunidades valorizando e promovendo suas práticas. Porém, com base em Marlet (2005), o outro lado desse encontro entre diferentes culturas pode ser a ocorrência da homogeneização cultural e consequente influência na sustentabilidade cultural dessa sociedade tradicional.

Entende-se que a transferência de experiências quando direcionada não apenas às escolas mas aos diversos espaços de divulgação da cultura brasileira pode contribuir para a valorização desses povos culturalmente diferenciados e fomentar novas perspectivas para a geração atual e futura, levando-as ao reconhecimento e consciência da importância da continuidade de saberes e práticas seculares que representam o seu patrimônio, identificando pessoas e seus territórios e também gerando renda à inúmeras famílias. Nesse sentido, as novas formas do design, como um pensar responsável e contemporâneo, com foco na abordagem sistêmica, consideram necessidades presentes pensando nas futuras. Assim, podem trazer à tona reflexões acerca de aspectos de ordem sociocultural em diálogo com as diversidades étnicas.

\footnotetext{
${ }^{1}$ Itamatatiua fica a $70 \mathrm{~km}$ da cidade de Alcântara, sede da comunidade, e a $90 \mathrm{~km}$ da capital do estado, São Luís.

2 O Programa Brasil Quilombola integra um conjunto de políticas governamentais de apoio às comunidades quilombolas sob coordenação da Secretaria Especial de Políticas de Promoção da Igualdade Racial (SEPPIR). Neste apresentam-se meios institucionais e jurídicos dirigidos aos quilombolas em conformidade com um quadro de demandas ou necessidades, como por exemplo: titulação e regularização do território, educação, segurança alimentar, saúde e cultura. (REIS, 2010).
} 
Diante do exposto questiona-se: Como o design com base na abordagem sistêmica pode fomentar a sustentabilidade cultural do quilombo de Itamatatiua tendo em vista o respeito às tradicionais formas de transferência intergeracional de experiências? Considerando a problemática apresentada que resultou na referida questão, o objetivo deste artigo consiste em apresentar, mediante pesquisas com base na abordagem sistêmica do design, a sintetização de dados e sistematização de interações que venham contribuir para o desenvolvimento de ações voltadas à comunidade de Itamatatiua. Este estudo justifica-se ao vislumbrar a participação do designer em um processo de mudança, por meio do diálogo e da ação conjunta entre as percepções das ceramistas de Itamatatiua e o conhecimento científico.

\section{Procedimentos Metodológicos}

Esta pesquisa caracteriza-se como participativa com ênfase na relação colaborativa entre pesquisador e pesquisados objetivando o conhecimento tácito desenvolvido por quem participa do processo (MORAES; SANTA ROSA, 2012). O estudo desenvolveu-se conforme os preceitos da pesquisa participativa com foco na abordagem sistêmica do design e delineou-se de forma qualitativa e descritiva, por envolver pessoas, fenômenos, aspectos da realidade, explorando a complexidade das ideias e do comportamento humano (MARCONI, LAKATOS, 2011). Portanto, a opção metodológica recaiu sobre a História Oral. Segundo Freitas (2006, p.18) "é um método de pesquisa que utiliza a entrevista e outros procedimentos articulados entre si, no registro de narrativas da experiência humana". Sendo assim, considerou-se a técnica de contação de história para levantamento de narrativas, como forma de despertar no pesquisador o olhar sobre histórias de vidas e trabalho das mulheres ceramistas do quilombo de Itamatatiua.

O levantamento de narrativas limitou-se às idosas e jovens adultas que hoje dominam as práticas artesanais locais. Essas mulheres foram não apenas ouvidas, mas também observadas de forma participante. A contação de história ou Storytelling, nesse processo, vem aumentar a coesão entre o designer e o artesão (MORAES; SANTA ROSA, 2012). O registro das narrativas foi realizado por meios audiovisuais, seguido de elicitações e transcrições das falas. Esses procedimentos citados aliados às pesquisas bibliográficas planificaram a pesquisa levando à caracterização do local e pessoas pesquisadas, considerando como requisito eletivo: a intergeracionalidade dos saberes e práticas tradicionais mantidas pelas mulheres ceramistas mediante suas narrativas.

\section{Contação de história: intergeracionalidade como sustentabilidade cultural}

A tradição oral baseia-se na concepção do homem e do seu lugar e revela-se de acordo com as aptidões humanas. Para Hampâté Bâ (2015), segundo o autor, contar histórias é uma prática ancestral que consolida o imaginário coletivo em uma rede formada por narradores e ouvintes. A narrativa oral permanece viva principalmente entre grupos sociais como, indígenas, africanos, asiáticos e árabes. Nesses grupos ressalta-se o papel dos contadores de histórias na formação dos indivíduos, detentores da sabedoria, são transmissores da memória, das tradições e alimentam o imaginário do coletivo (MEDEIROS; MORAES, 2015). Narrar sobre modos de viver e produzir, diz respeito não apenas às memórias do passado, mas também ao presente e futuro ao provocar os observadores, em um processo de transferência de experiências e educação contínuo que não se encerra em si, pois consiste em um intercâmbio de informações entre culturas e gerações diversas.

A transmissão de informações em Itamatatiua tem forte ligação com o ato de contar 
histórias, prática que representa a passagem de saberes, fazeres, modos de ser e viver de um território para o povo que nele vive. Fazer artesanato em cerâmica, para as mulheres de Itamatatiua, representa conhecimentos passados de geração a geração, especialmente de mulheres para mulheres caracterizando-o como tradicional ${ }^{3}$. A oratória em rodas de conversa, era o principal instrumento de transmissão intergeracional cultural. Hoje as narrativas voltadas 'as novas gerações se diluem ao dividir espaço com os ensinamentos das escolas que nem sempre condizem à cultura local.

$\mathrm{Na}$ comunidade quilombola de Itamatatiua o imaginário e narrativas se convertem em representações, em artefatos que logo as crianças e jovens começam a experienciar ao reproduzirem os movimentos das artesãs mais velhas, culminado na intergeracionalidade cultural, um processo de interações sociais entre indivíduos de idades distintas. A modelagem de produtos em cerâmica é uma prática vinculada ao simbolismo das histórias contadas. Nesse contexto, as mulheres ceramistas são as detentoras e depositárias da arte e ofício de produzir esses artefatos. AVIZ (2015), ao tratar, em estudo, sobre as negras vozes dos quintais, no sentido de histórias orais, ressalta a importância do contador de histórias sobre as experiências de uma cultura, a vivência na oralidade dessa, e o poder de fazer o receptor refletir.

Partindo do princípio de que a história de vida, de trabalho, de luta e os sentimentos são materializados em produções de artefatos no quilombo. Com base em Todaro (2009) sobre relações intergeracionais, a convivência com idosos, a apreensão de suas práticas e conhecimentos, assim como da atitude dos adultos em relação à geração anterior, fundamentam as atitudes dos jovens e crianças em relação à esses objetos sociais e em relação a si mesmos quando forem adultos e posteriormente idosos. Nesse sentido o ensinamento entre gerações, traduzidos em contos, histórias sobre o vivido, configuram-se como repasse de experiências. Prática comum nos quilombos onde, ainda na infância, os membros das comunidades começavam a aprender sobre sua cultura ${ }^{4}$. Portanto, considerando as novas formas do design com foco na abordagem sistêmica, importa resgatar essa tradição com vistas a sustentabilidade da cultura de Itamatatiua, ainda que a prática da transmissão oral sofra inovações.

A sustentabilidade cultural das sociedades tradicionais é incentivada pelo governo ao garantir o direito e proteção às manifestações culturais populares, indígenas e afro-brasileiras na Constituição de 1988, no Artigo 215 da Seção II referente a cultura: “O Estado garantirá a todos o pleno exercício dos direitos culturais e acesso às fontes de cultura nacional, e apoiará e incentivará a valorização e a difusão das manifestações culturais". (CONSTITUIÇÃO BRASILEIRA. Edição técnica, 2007, p.139). O parágrafo $3^{0}$ do mesmo Art. Trata do Plano Nacional de Cultura do país integrado à ações do poder público que conduzem, entre outros, à valorização do patrimônio cultural brasileiro e valorização da diversidade étnica e regional.

Nesse sentido, entende-se, que estudos em design voltados às comunidades quilombolas,

\footnotetext{
${ }^{3}$ Segundo Abbonizio (2009, p. 25), o artesanato tradicional é o "Conjunto de artefatos mais expressivos da cultura de um determinado grupo, representativo de suas tradições, porém incorporados à sua vida cotidiana. Sua produção é, em geral, de origem familiar ou de pequenos grupos vizinhos, o que possibilita e favorece a transferência de conhecimentos sobre técnicas, processos e desenhos originais. Sua importância e seu valor cultural decorrem do fato de ser depositária de um passado, de acompanhar histórias transmitidas de geração em geração, de fazer parte integrante e indissociável dos usos e costumes de um determinado grupo."

4 Estudos de Pereira (2011) apontam para mudanças de costumes que afetam as relações intergeracionais e consequentemente a transmissão de conhecimentos nas comunidades tradicionais quilombolas do maranhão.
} 
que sigam os procedimentos metodológicos da história oral apoiados na técnica de contação de história, desenvolvidos com foco na abordagem sistêmica, podem resultar na valorização da autorepresentação dos remanescentes dos quilombos como estratégia para geração de meios, artefatos ou sistemas, que venham contribuir para a continuidade da cultura desses grupos sociais mediante a transmissão de experiências, saberes, práticas e formas de viver desses grupos sociais.

\section{Abordagem sistêmica do design}

O design com foco na abordagem sistêmica, segundo Portas (1993), resulta no alargamento da visão do designer, pois esse passa a não se limitar ao objeto em si e busca compreender não somente os elementos que constituem o sistema, mas também às relações que se estabelecem entre estes e os resultados dessas interações. Portanto, a atuação do designer pode integrar um sistema de informação cujos componentes são os atores sociais e instituições que se relacionam em redes de produções locais, permitindo trocas dentro de uma comunidade criativa (Martorano, 2012). Portanto, o principal desafio do designer nesse contexto, é desenvolver soluções mediante visão abrangente do projeto, envolvendo produtos e serviços de forma conjunta e sustentável. Nesse sentido pensar o design sistematicamente quer dizer fazê-lo de forma integral e em rede, ou seja, posicionando o designer em um sistema (Bürdek, 2006) que envolve pessoas, sua cultura imaterial e a materialização dessa em artefatos e serviços.

Com base no exposto, entende-se que o processo projetual gerido por um designer demanda desenvolvimento em etapas de expansão de ideias seguidas de etapas de refinamento. Aros (2016), apresenta o processo de design de um Guia Projetual ${ }^{5}$ (desenvolvido no Núcleo de Abordagem Sistêmica do Design - NAS Design) para Comunidades Criativas que consiste em um sistema de fases e etapas. Iniciando com o Start, que consiste em um momento de prospectar informações preliminares para seguir para as fases: Sentir, Agir e realizar A fase sentir inicia-se com a abordagem empática para compreensão da realidade de um grupo social e envolve as etapas: 1) sensibilização, encontro com a comunidade para desenvolver um projeto colaborativo com membros da comunidade, designer e outros atores; 2 ) verificação, momento em que o foco é a voz da comunidade e 3 ) delimitação, alinhamento das demandas às possíveis soluções. A Fase Agir diz respeito as etapas: 1) concepção, indica a geração de soluções tangíveis; 2) apresentação, das soluções desenvolvidas junto da comunidade e 3) Feedback, análise e eventuais ajuste pela equipe, retorno para apresentação, e aprovação com partes interessadas presentes. Por fim, a fase realizar, engloba 1) fechamento, após aprovação das soluções, representantes da comunidade ficam encarregados de dar prosseguimento a produção com apoio do designer e/ou outros da equipe, se for necessário e 2) vínculo aberto, possível retorno a etapa de feedback da fase Agir para adequações conforme retorno da comunidade. Para tal, importa o contato com a comunidade e demais envolvidos no processo.

O desenvolvimento de projetos, considerando a abordagem sistêmica do design, compreende o ambiente de atuação como um todo, suas relações de interação com o meio, com as pessoas e com todos os sistemas com o qual se relaciona. A abordagem sistêmica sugere que um sistema, ou uma complexidade organizada, é definido pela existência de interações e interlocuções entre os atores envolvidos nesse. Portanto, demanda-se estudos não somente sobre as partes e processos isoladamente, mas também da organização e dos sujeitos que interagem

\footnotetext{
${ }^{5}$ Guia Projetual NASDesign para Comunidades Criativas. Acesso em: http://nasdesign.herokuapp.com.
} 
nessa dinâmica. A Teoria Geral dos Sistemas (TGS) de Bertalanffy (1977), e as teorias do pensamento sistêmico (ANDRADE, 2006), como forma de abordagem, consideram a totalidade dos sistemas tendo em vista o comportamento das partes diferentes isoladamente e considerando o todo.

Entende-se sistema como um conjunto de elementos, conhecimentos, experiências que são interconectados, de modo a formar um todo organizado. Quine (1969), citado por Dutra (2005), parte da ideia, tendo como referência o seu famoso artigo: "Epistemology Naturalized", de que somos reflexo ou sofremos alterações resultantes das relações com o ambiente físico a nossa volta, ou seja, todo nosso conhecimento factual depende de experiências consistentes advindas de um mundo composto de entidades relacionadas. Sendo assim, trata-se de um fenômeno da entrada (input) de dados e consequente resultante do processamento desses em saída (output). Portanto, o design envolve teoria e prática de forma sistemática na aplicação de métodos, técnicas e imaginação no desenvolvimento de produtos, serviços e sistemas mediante um conjunto de conhecimentos interdisciplinares e interconectados, de modo a formar um todo organizado.

Esses elementos que representam partes e que formam o todo podem ser representados por redes de conhecimentos e relações sob o qual se organiza uma estrutura onde se insere, entre outros, instituições políticas, econômicas, morais que regem uma sociedade. Nesse processo o êxito do designer depende das respostas não apenas do usuário individual ou grupo social pesquisado, mas também de uma comunidade organizadora. Manzini (2008) argumenta que o design assume uma abordagem sistêmica quando a tarefa de desenvolvimento de um novo produto ou serviço envolve a participação, conhecimentos e experiências de todos os interessados nos resultados e benefícios.

\section{Desenvolvimento da Pesquisa}

Este estudo seguiu etapas relativas a fase sentir. Portanto, conforme o fluxo (ver fig. 1) de desenvolvimento, realizou: levantamento, registro de narrativas, sintetização e sistematização dessas considerando o âmbito cultural, os aspectos evidenciados nas narrativas e sugestões de abordagens do designer com vista à sustentabilidade cultura de Itamatatiua (ver quadro 1). Posteriormente foi apresentado esquemático do estudo com foco na abordagem sistêmica (ver fig. 3); seguido de uma visão mais ampla do sistema de transferência de informação relativa as experiências de vida e trabalho no quilombo, registado em mapa conceitual (ver fig. 4). Por fim, um diagrama que relaciona os principais elementos geradores do valor inerentes aos produtos ou serviços de um sistema com vistas à sustentabilidade cultural de Itamatatiua (ver fig. 5).

Figura 1 - fluxo do desenvolvimento do estudo

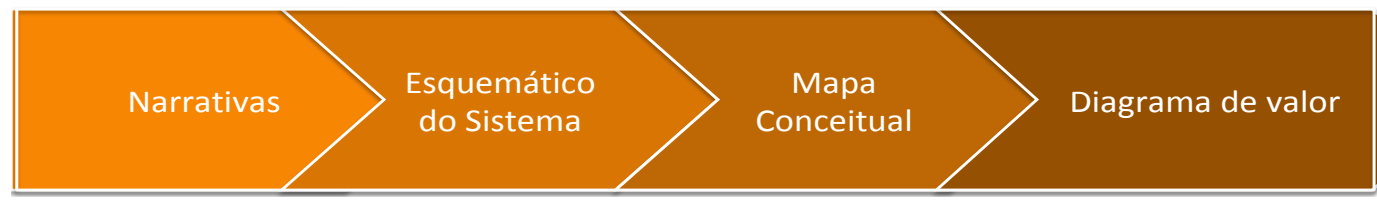

Fonte: Elaborada pelos autores com base em dados da pesquisa

\subsection{Contação de histórias em Itamatatiua}

A contação de histórias consiste em uma forma de resgatar histórias muitas vezes já esquecidas e também a escuta da própria voz, a partir da oratória dos chamados antigos. 
Conforme Aviz (2015), os quintais afro-brasileiros, considerando como espaços de manifestações culturais mediante expressões orais e corporais foram enfraquecendo por estarem também relacionados à uma longa história de escravidão. Em Itamatatiua as narrativas das artesãs revelaram emoções, sentimentos e experiências e tratam de aspectos que podem trazer impactos a sustentabilidade cultural desse quilombo.

A origem do quilombo e herança cultural deixada pelos ancestrais que faziam cerâmica, a transmissão dos saberes e práticas que identificam esse grupo, as interações com o turista e suas implicações são temas abordados nas histórias orais. Segundo narrativas ${ }^{6}$ desde que os escravos chegaram àquele território começaram a trabalhar com a argila.

\begin{abstract}
"Essa cerâmica aqui foi desde os tempos antigos" "A muitos anos. Com oito anos eu já fazia cerâmica!". "Acho que desde quando foi fundado aqui, começaram a fazer por precisão (se referindo aos antepassados). Contam que eram fugitivos que fugiram de Alcântara e procuravam um mato bem grande (...) e aí quando chegavam bem longe eles faziam as suas casinhas (com barro) e iam morar. Aí por necessidade, alguém sabia fazer, e tinha o barro aqui, né? Por necessidade, porque não tinha panela nem nada. Por necessidade eles começaram a fazer as peças pra fazer a comida deles." ${ }^{7}$
\end{abstract}

Essa antiga prática dos remanescentes do quilombo, conforme narrativas, apresenta-se ameaçada pelo distanciamento dos jovens. Tal fato leva à quebra no processo de transmissão da tradição secular, passagem parentais, intergeracionais, especialmente de mulheres idosas para jovens e crianças. Comprometendo dessa forma a sustentabilidade cultural. Nesse sentido as artesãs narram como aprenderam sobre a atividade, sua representatividade e também sobre a perspectiva de continuidade da atividade:

(...) "era a única solução que tinha nós vivíamos disto, isso aí era o pão de nós viver, se manter. Aí eu comecei a fazer e, com essa cerâmica, eu criei meus filhos" (...)“Aprendi com a minha tia, com a idade de 12 anos. Eu faço, a minha irmã, a minha prima (...) então a gente fica assim, que é pra as meninas mais jovens irem pra lá (centro de produção) que é pra quando as mais velhas não puderem mais, pra não terminar a tradição, porque senão, termina. E como vai ser né? Porque tem muita gente que vem, é pra olhar essas coisas, vem olhar a argila, vem olhar a louça. Todo mundo acha bonito e tudo., ${ }^{8}(. .$.$) "pra$ mim representa o Quilombo por que foi o passado, né? Aí, Por isso que eu não gosto de (silêncio) que a cerâmica acabasse. Porque foi o passado de minha avó, meus avós. Uma coisa que a gente poderia nunca deixar acabar. Eu fico com pena de terminar esse trabalho de cerâmica. Uma coisa muito marcada aqui."(...) "as vezes a gente sente assim, tem coisa dos jovens que não se interessam muito. Algum se interessa. Aqui (se referindo ao centro de produção) a gente tem só três jovens que trabalham aqui.." (...) "essa cerâmica, se agente não tiver cuidado, daqui a pouco não tem ninguém que queira". ${ }^{10}$

As narrativas também apontam a presença de pessoas estranhas à comunidade que, segundo as artesãs, vão à Itamatatiua para conhecer o quilombo e suas práticas. Essas visitas caracterizam o turismo rural ${ }^{11}$ que é mais um fenômeno percebido na comunidade de Itamatatiua

\footnotetext{
${ }^{6}$ Eloisa. Dados de entrevista realizada em 17 de junho de 2013.

${ }^{7}$ Neide. 17 de junho de 2013. Entrevista: Raquel Noronha. gravação e transcrição: Glauba Cestari.

${ }^{8}$ Maria dos Santos de Jesus. 19 de junho de 2013. Entrevista: Raquel Noronha. Gravação e transcrição: Glauba Cestari

${ }^{9}$ Eloisa. 19 de junho de 2013. Entrevista: Raquel Noronha. Gravação e transcrição: Glauba Cestari

${ }^{10}$ Neide. 19 de junho de 2013. Entrevista, gravação e transcrição: Glauba Cestari.

${ }^{11}$ A procura por visitas à espaços rurais (caracterizado como o bom turismo) cresce, em substituição ao turismo massificado (caracterizado como o mau turismo), devido ao interesse pelo tradicional, pelo autêntico. Esse,
} 
e esse vende a ideia de contato com os quilombolas e com um ambiente que configura "o passado". Ao longo da análise das histórias orais nota-se, quanto a presença do turista, motivações e novas possibilidade trazidas acarretando em inovações sem eliminar as formas tradicionais. O pote (ver fig.2), a título de exemplo, hoje é produzido em menor quantidade e, de objeto utilitário, ganha novo status.

\begin{abstract}
"Algumas pessoas que compra pra fazer decorações. Antigamente todo mundo comprava porque não tinha balde de plástico. Não tinha água encanada. A pessoa ia como daqui até a pista busca água com pote". ${ }^{12}($ (...) “Porque aqui não vinha turista. Agora a gente resolveu fazer as peças menores porque o turista vai sair e não vai levar um pote né? Um pote grande. Aí, a gente tomou essa atitude de fazer outras peças menores.."13
\end{abstract}

Figura 2 - Artesã moldando pote

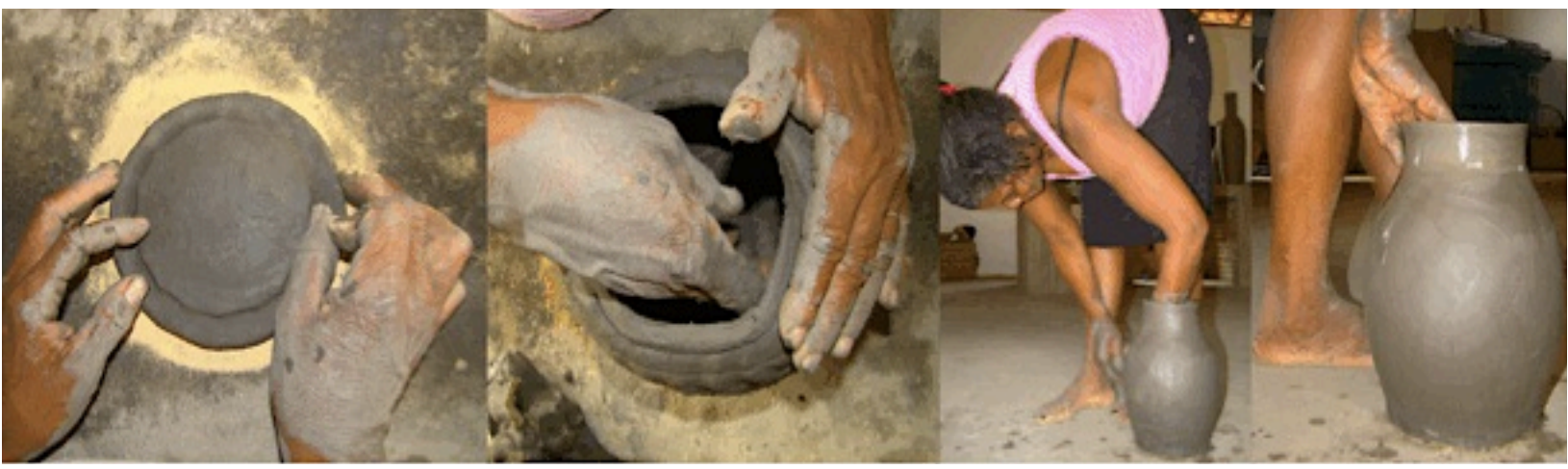

Fonte: produção do autor para a pesquisa

Diante das histórias contadas importa o fato de que o território onde vivem esses povos é também o local onde constroem suas identidades, preservam a memória coletiva e renovam, mediante intergeracionalidades, seus conhecimentos e tradições. Enfatiza-se que as experiências transmitidas pelas ceramista de itamatatiua envolvem linguagens que fazem parte do sistema de comunicação entre pessoas que pode se caracterizar como: verbal ou não verbal. Com base em Petterson (2002; 2012. apud. Aros, 2016), a primeira diz respeito a linguagem falada, escrita ou tátil. A segunda, por sua vez, entre outras, refere-se à auditiva e visual. Em sua totalidade, as narrativas instigam reflexões sobre o desenvolvimento de melhores formas de interações e intervenções que tenham como foco pessoas, sua cultura e especificidades de um grupo social. Portanto, a contação de história apresenta-se como importante ferramenta para o designer na prospecção de informações que vêm servir como base fundamental à proposições de ações planejadas com foco na Abordagem Sistêmica. Nesse contexto, pesquisas e ações terão mais chances de serem aplicáveis a realidade sóciocultural de comunidades.

O quadro 1 apresentam a sintetização dos dados levantados relacionando os aspectos evidenciados nas narrativas, a abordagem dessas e as sugestões de estratégias ou possíveis abordagens do designer com foco na sustentabilidade cultural do quilombo de Itamatatiua.

movimento iniciado nos anos de 1980 e 1990, passa a ser a opção de turismo diferenciado que permite o visitante se desligar do mundo material do turismo massificado. (JOAQUIM, 1997)

${ }^{12}$ Eloisa. 17 de junho de 2013. Entrevista, gravação e transcrição: Glauba Cestari

${ }^{13}$ Eloisa. 17 de junho de 2013. Entrevista, gravação e transcrição: Glauba Cestari. 
Quadro 1 - âmbito cultural, aspectos das narrativas e abordagens do designer.

\begin{tabular}{|c|c|c|}
\hline Âmbito & Aspectos das narrativas & Abordagens do Designer \\
\hline Cultural & $\begin{array}{l}\text { As narrativas tratam da origem do } \\
\text { quilombo; aspectos relacionados a } \\
\text { transmissão de informações acerca } \\
\text { das práticas que identificam } \\
\text { Itamatatiua; interações com o } \\
\text { outros atores sociais; } \\
\text { distanciamento dos jovens e } \\
\text { também sobre as impressões das } \\
\text { ceramistas sobre o presente e } \\
\text { futuro da comunidade tendo em } \\
\text { vista a continuidade dos saberes e } \\
\text { práticas, patrimônio da localidade. }\end{array}$ & $\begin{array}{l}\text { O Designer, junto à comunidade e outros } \\
\text { atores colaboradores, podem valorizar os } \\
\text { saberes e fazeres de Itamatatiua mediante } \\
\text { projetos que comuniquem e contextualizem a } \\
\text { imagem do quilombo, de suas histórias e dos } \\
\text { produtos que representam essas narrativas. } \\
\text { Fomentar Interações e interlocuções com } \\
\text { artesãs na criação de soluções inovadoras } \\
\text { que atraiam as novas gerações à } \\
\text { continuidade das práticas locais e respondam } \\
\text { as demandas do presente respeitando } \\
\text { motivações, potencialidades locais e } \\
\text { elementos de referência cultural. }\end{array}$ \\
\hline
\end{tabular}

Fonte: Elaborada pelos autores com base em dados da pesquisa.

Retomando ao Quadro 1, evidencia-se nas narrativas das artesãs o afastamento da nova geração de suas raízes culturais. Nesse sentido, tendo como referencia Andrade (2006), no pensamento sistêmico o indivíduo está inter-relacionado a sistemas maiores. Portanto, considerando a nova geração como parte criativa no sistema; se esse não crescer conhecendo e valorizando suas raízes culturais, o todo é afetado negativamente. Portanto, os jovens podem não só contribuir criativamente para escrever o futuro de Itamatatiua, como também podem despertar um novo olhar para com o presente tendo em vista as relações sociais internas e com outros atores. Assim, visualizar o sistema e os indivíduos que fazem parte desse implica na compreensão das estruturas internas (o povoado, seus moradores formas de produzir e viver) e das inter-relações com as estruturas externas aos limites do quilombo (o designer e outras pessoas, organizações ou entidades públicas ou privadas).

Para Andrade (2006), sobre visão compartilhada e na perspectiva do pensamento sistêmico, quanto mais o designer se aproximar da realidade e estrutura sistêmica de uma comunidade mais obterá energia criativa para transformar um realidade complexa em um futuro desejado, mediante a visão do todo e dos esforços em torno de um propósito comum. Nesse projeto os membros da comunidade são participantes de um processo em torno da alavancagem sistêmica. Para Andrade (2006), o pensamento sistêmico é praticado em grupo, pois somente assim pode-se aprender junto e ter uma visão ampliada do sistema explorando suas diversas partes e facetas. Estudos e ações do design tornam-se mais eficazes considerando o coletivo, tendo em vista as influências mútuas entre indivíduo, grupo e organização maior.

\subsection{Esquemático do Sistema da continuidade dos saberes do quilombo}

Tendo como referência Silva (2012) acerca dos tipos de sistemas, esses podem ser classificados entre abertos e fechados. O primeiro apresenta relações de intercâmbio com o meio externo, através de entradas, processos e saídas (inputs, processos e outputs). O Segundo, por sua vez, não realiza intercâmbio com o meio externo que o circunda. Sendo assim, não recebe nenhuma influência do ambiente e também não influencia o ambiente. Este estudo apresenta um sistema aberto e o esquemático desse, desenvolvido com base em Bertalanffy (1977), pode ser visto na figura 3. 
Figura 3 - Esquemático de modelo sistêmico

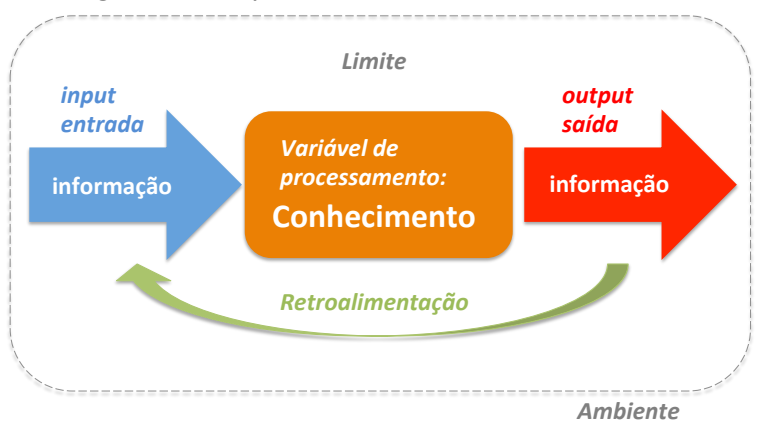

Fonte: Adaptado de Bertalanfy (2008) pelos autores

Para Aros (2016), o processo de design sob abordagem sistêmica consiste em um sistema de manipulação de informações que gera novas informações sob a forma de produtos e/ou serviços. Sugerindo, desta forma, inputs, processamentos, outputs e retroalimentações. A pesquisadora acrescenta que a transmissão de informação e o processo de conhecimento gera novas informações. Tendo como referencia os estudos de Aros (2016), sob o olhar da abordagem sistêmica, a informação compõe um fluxo de mensagens que entram e saem do sistema cognitivo resultando no conhecimento que é balizado pelo compromisso, crenças, cultura do sujeito. Sendo assim informação e conhecimento estabelecem no sistema uma relação cíclica.

No contexto deste estudo entende-se o ato de transferência de informações no quilombo como a passagem de dados de uma pessoa a outra. Desta forma a contação de história consiste em narrativas orais e visuais, mediante a fala e artefatos, que transpõem ao receptor impressões relacionadas as experiências vividas por gerações de mulheres ceramistas. Portanto, pode-se afirmar , com base em Aros (2016), que o conhecimento tácito dessas artesãs, em sua dimensão epistemológica, corresponde à suas habilidades e capacidades informais ou Kow-how. Esse pode torna-se explicito e transmissível mediante codificação em uma linguagem sistemática. Já em outra dimensão do conhecimento, a antológica, visualiza-se essas mulheres como entidades que criam, transmitem, expandem e cristalizam seus saberes transformando o conhecimento pessoal em conhecimento organizacional formado por um grupo de artesãs podendo chegar a outros níveis de interações e criação de conhecimento gerando novas informações e conceitos que beneficiem os atores envolvidos nesse processo e sistema.

\subsection{Mapa Conceitual: transferência de informações e interações}

Nesta pesquisa, o design insere-se como abordagem sistêmica territorial, no contexto dos quilombos de Alcântara (Maranhão). Evidencia-se que a importância do design está tanto em promover ações em comunidades, quanto em registrar as interações e os desdobramentos dos encontros entre os atores integrantes de um sistema. Portanto apresenta-se nesta proposta um mapa conceitual ${ }^{14}$ que representa graficamente um sistema de interlocuções intergeracionais e

\footnotetext{
${ }^{14}$ Para Martorado (2012), mapas conceituais são utilizados como uma estrutura esquemática e são considerados estruturadores de conhecimento, considerando que pode mostrar o conhecimento sobre um tema ou sistema sob a estrutura cognitiva do autor. Lauro (2014) acrescenta que sua criação parte de uma pergunta focal, desse ponto podese seguir para conceitos e criação de proposições. Essa estrutura é direcionada por setas que indicam o sentido da leitura ou fluxo cognitivo do autor.
} 
interações entre o designer pesquisador, as pessoas quilombolas, em especial mulheres ceramistas, e redes de competência tendo como ferramenta a contação de histórias para transferência de experiência e continuidade da intergeracionalidade dos saberes é práticas com vistas à sustentabilidade cultural.

Figura 4 - Mapa Conceitual: sistema de transferência de informação e interações entre atores sociais

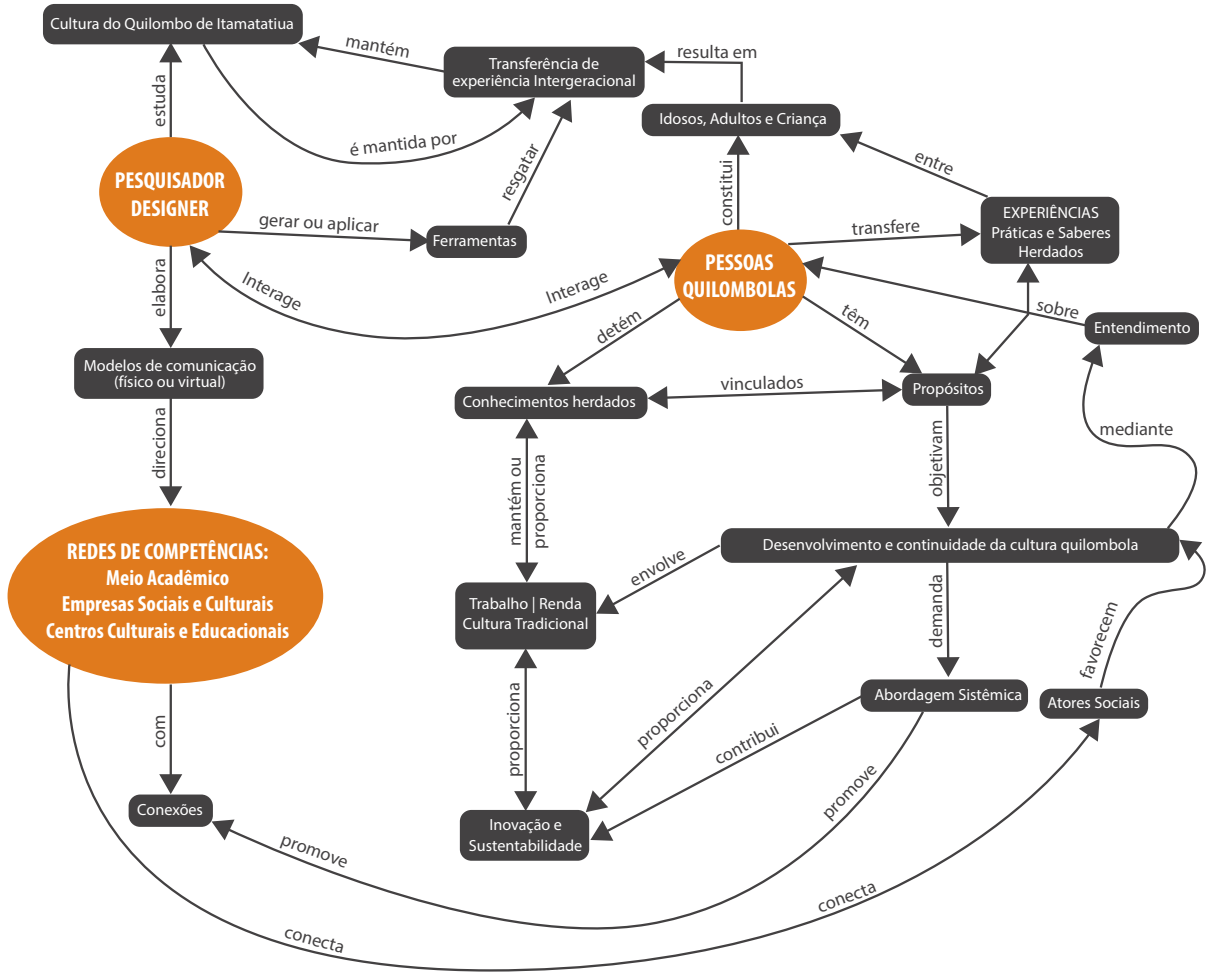

Fonte: produção dos autores para a pesquisa

No mapa conceitual acima sugere um modelo de sistema de interlocuções e interações entre atores sociais, o designer, comunidade quilombola e redes de competências. Parte-se do princípio de que o designer pesquisador e as mulheres ceramistas do quilombo interagem entre si no sistema de interlocuções e interações sociais para estimular a transferência de saberes e experiências tendo como objetivo a sustentabilidade cultural do território quilombola pesquisado. $\mathrm{Na}$ perspectiva da abordagem sistêmica, o mapa sugere, com base nas pesquisas realizadas e narrativas, relações entre pessoas, serviços, informações e conhecimentos destinados às partes interessadas: Redes de Competência, o pesquisador designer e as pessoas quilombolas. Nesse sistema, importa a voz de quem detém os saberes herdados vislumbrando, em especial, o repasse de vivências às novas gerações em um ciclo de transmissão de informação (input), geração de conhecimentos e práticas concretizadas em produtos materiais, artefatos cerâmicos, e imateriais, manifestações religiosas, danças, músicas do quilombo para redes de pessoas interessadas (output) e retorno à própria comunidade (input) em um processo de retroalimentação do sistema, no qual a transferência de informações ou experiências mantém a cultura quilombola e é mantida por ela.

Dentro do contexto em estudo, o pesquisador designer pode contribuir com a habilidade de gerar ferramentas que resgate a tradição de transferência de experiências de vida intergeracional por meio das narrativas, em vias de extinção. Essa prática secular de transmissão 
de informação mantém viva a cultura de Itamatatiua e essa, por sua vez, é mantida pela intergeracionalidade. Tendo como referência Andrade (2006), os sistemas representam nossas organizações, nossas cidades, comunidades, conhecimentos. Esses adoeceram se não desenvolverem a capacidade de se adaptar e de se auto-renovar continuamente

O designer, como planejador e gestor de um sistema de interlocuções e interações entre atores sociais diversos, ao se aproximar de uma comunidade de forma participativa e em rede com o meio acadêmico, empresas sociais e culturais, centros culturais e educacionais poderá beneficiar a localidade instigando a elaboração de modelos de comunicação física ou virtual direcionada as redes de competências voltadas ao fomento da cultura brasileira. Essas redes, por sua vez, podem conectar-se à diversos atores sociais que venham valorizar e favorecer o desenvolvimento e continuidade da cultura quilombola mediante o entendimento sobre as mulheres ceramistas do quilombo, seus conhecimentos herdados e seus propósitos, tendo em vista o passado, o presente e perspectivas para o futuro.

No quilombo as mulheres ceramistas detém conhecimentos que proporcionam trabalho e esse, concomitantemente, mantém os saberes e práticas mediante os artefatos resultantes, por serem a materialidade do conhecimento. Ao olhar para o futuro, essas mulheres tem como propósito lutar pela manutenção da sua cultura, ainda que para isso tenham que passar por inovações, pois em seus relatos orais entendem que o desenvolvimento está nas mãos das novas gerações e o novo será necessário para atrair os jovens, mas temem pela descaracterização de seu patrimônio ${ }^{15}$. Fato que justifica a importância de um sistema que aproxime os atores envolvidos em projetos voltados a comunidades tradicionais. Esses projetos devem prezar pela voz de quem sabe e considerar os beneficiários como participantes ativos para que as soluções desenvolvidas para sanar problemas identificados sejam aplicáveis a realidade e propósitos dos mesmos.

\subsection{Diagrama de Valor}

O mapa apresentou a transferência de informação como forma de valorização, disseminação e perpetuação da identidade patrimonial do quilombo sugerindo caminhos para a sustentabilidade cultural da comunidade pesquisada. Esse evidencia interações entre experiências de pessoas e ofertas de organizações, gerando valor. Importa destacar que nessas relações espera-se algum benefício, quanto ao uso de produtos e serviços ofertados. O benefício tem valor e esse envolve uma moeda de troca que pode ser dinheiro, tempo, atenção, emoções, conhecimento, outros. Segundo kalbach (2017), para organizações sobreviverem, precisam capturar algum valor com suas ofertas. Nesse sentido, o autor acrescenta que a criação do valor é bidirecional e está na interseção da interação entre pessoas e organização provedora de serviços. É nesse processo que experiências de pessoas cruzam com ofertas de uma organização.

Neste estudo, o valor é a informação transmitida geradora de conhecimento. Com base em Santana (2017), O contexto, conteúdo e usuário se apresentam como elementos construtores da informação (inf). Nesse interim, o usuário representa os utilizadores da informação. Esse elemento consiste nas partes interessadas apresentadas no mapa conceitual (comunidade

\footnotetext{
15 “O patrimônio está ligado ao tempo por sua evolução e por seus ritmos. Ele tem um passado, um presente e um futuro. Se o desenvolvimento se efetua no presente, portanto a partir de um patrimônio constatado a um dado momento, ele não pode ignorar suas origens e não pode igualmente se limitar a consumi-lo sem nada criar de novo. Quanto aos ritmos, ou ao menos aos ritmos endógenos, eles são produto e resultado do patrimônio. Não se pode fazer nenhum desenvolvimento sem levar em conta os ritmos da vida local, que fazem parte integrante da cultura viva da população" (Varine, 2013, p.20).
} 
quilombola, visitantes, pesquisadores, empresas ou organizações sociais, culturais e educacionais, stakholders); o contexto compreende aspectos ou dimensões socioculturais e econômicos do ambiente, tais como, as políticas culturais, estratégias e processos de organização, objetivos, missões e, por fim, o conteúdo diz respeito a documentos, imagens, artefatos, mídias, ferramentas que os usuários utilizam ou precisam encontrar.

Figura 5: Diagrama - informação como valor

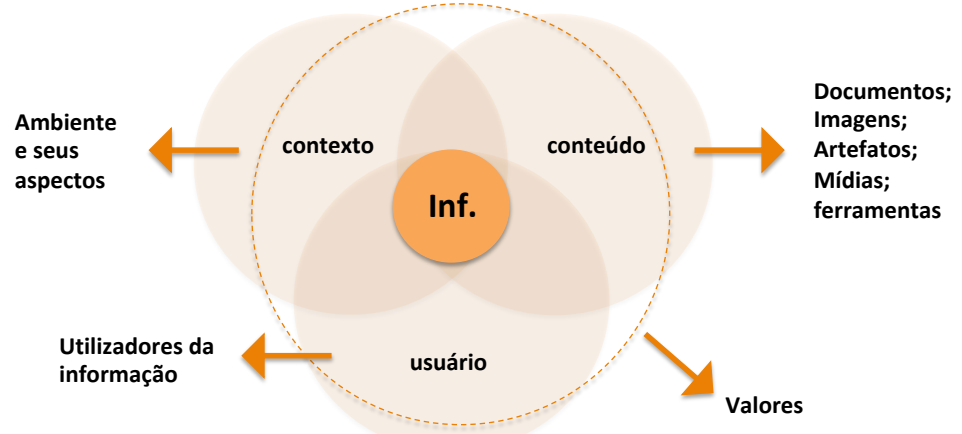

Fonte: diagrama desenvolvido pelos autores com base em Santana (2017)

\section{Conclusão}

Em um país conhecido por sua diversidade cultural se faz pertinente refletir sobre estratégias de valorização e manutenção de saberes e práticas, advindos de variadas etnias, que, por sua vez, permitem geração de trabalho e renda à inúmeras comunidades produtoras de artefatos artesanais tradicionais, fruto de conhecimentos herdados ou adquiridos. Assim, esta pesquisa procurou enfatizar o design, sob abordagem sistêmica, e a importância da participação do grupo pesquisado (representado em mapa conceitual) nas formas de interlocuções e interações que venha favorecer o desenvolvimento de projetos para comunidades tradicionais. Dessa forma, o design insere-se, no contexto desse trabalho, como um participante em um processo de valorização das diversidades e inovação de uma cultura quilombola secular. Nesse sentido os estudos realizados tiveram como base as narrativas das ceramistas, detentoras dos saberes de Itamatatiua.

Acredita-se que os resultados vêm contribuir, no meio acadêmico, colocando a tona a contação de história como instrumento a ser aplicado na abordagem sistêmica do design, considerando a transmissão de conhecimentos com vistas à perpetuação de práticas tradicionais. Espera-se, mediante este estudo realizado até o momento, estimular o desenvolvimento de novas pesquisas que reflitam sobre as interações do designer e outros atores com comunidades étnicas ou tradicionais sob um novo olhar com foco no homem e nos aspectos socioculturais, políticos e econômicos que formam um grupo e que podem afetar a sustentabilidade desse.

Considera-se importante para novas pesquisas e aprofundamento deste trabalho, em desenvolvimento, a identificação de pesquisas e ações do design voltadas a instrumentalização da educação, em especial, dos jovens e crianças do quilombo no intento de favorecer interlocuções entre gerações e perpetuação da cultura dos quilombos.

\section{Referências}

ABBONIZIO, M. A. O. Aproximação teórica das intervenções de no artesanato com os princípios 
pedagógicos de Paulo Freire: Caminhos para uma prática emancipatória. Dissertação. Universidade Federal do Paraná, Curitiba. 2009.

ANDRADE, Aurélio L., et al. Pensamento sistêmico: caderno de campo: o desafio da mudança sustentada nas organizações e na sociedade. Porto Alegre: Bookman, 2006. 488 p.

AROS, K. C. (2016). Elicitação do processo projetual do Núcleo de Abordagem Sistêmica do Design da Universidade Federal de Santa Catarina. (Dissertação de mestrado). Programa de Pósgraduação em Design e Expressão Gráfica. Universidade Federal de Santa Catarina, Florianópolis, SC. 2016. 103 p.

AVIZ, R. As negras vozes dos quintais: acordes da canção Moçambique-Brasil. $P$ 143-154. in MEDEIROS, F.H.N.; MORAES, T.M.R. Contação de histórias: tradição, poéticas e interfaces. São

Brasil. Constituição (1988). Constituição da República Federativa do Brasil: Texto constitucional promulgado em 5 de outubro de 1988. Brasília: Senado Federal, Subsecretaria de Edições Técnicas, 2007. 462 p.

BERTALANFFY, L. V. Teoria geral dos sistemas. Trad. de Francisco M. Guimarães. 3.ed. Petrópolis: Vozes, 1977.

CESTARI, G.A.V. Cerâmica do quilombo de Itamatatiua: Interações do design com o artesanato voltadas à sustentabilidade. Dissertação (Mestrado). Universidade Federal do Maranhão, Programa de Pós-Graduação em Design, 2014. 190 f.

DUTRA, L. H. de A. Oposições filosóficas: a epistemologia e suas polêmicas. Florianópolis, SC: Editora UFSC, 2005.

FREITAS, S. M. História Oral: possibilidades e procedimentos. 2.ed. São Paulo: Associação Editorial Humanitas, 2006.

Guia Projetual: NASDesign para Comunidades Criativas. Acesso: < http://nasdesign.herokuapp.com>. Em 19 de março de 2018.

HAMPÂTÉ BÂ, A. A tradição viva. p 155 - 188. in MEDEIROS, F.H.N.; MORAES, T.M.R. Contação de histórias: tradição, poéticas e interfaces. São Paulo: Edições Sesc São Paulo, 2015. - 544pp.

KALBACH, J. Mapeamento de experiências: um guia para criar valor por meio de jornadas, blueprints e diagramas. Rio de Janeiro: Alta Books, 2017.

LAURO, A. B. Abordagem Sistêmica e Gestão do Design na formação de uma rede integradora de serviços. Dissertação (mestrado). Universidade Federal de Santa Catarina. Programa de Pósgraduação em Design e Expressão Gráfica. Florianópolis, SC. 2014. 119 p.

MARLET, J. V. Diseño ecológico. Barcelona. Editora: Blume, 2005.

MORAES, A. M.; SANTA ROSA, J. G. Design Participativo, técnicas para inclusão de usuários no processo de ergonomia de interfaces. Rio de Janeiro: Rio Book's. 2012.

MARCONI, M. A.; LAKATOS, E. M. Técnicas de pesquisa: planejamento e execução de pesquisa, elaboração, análise e interpretação de dados. 7.ed. São Paulo: Atlas, 2011.

MARTORANO, M. Sistematização das atividades do NAS Design com foco na abordagem sistêmica para gestão de design. Dissertação (mestrado). Universidade Federal de Santa Catarina. Programa de Pós-graduação em Design e Expressão Gráfica. Florianópolis, SC, 2012. 110 p.

MEDEIROS, F.H.N.; MORAES, T.M.R. Contação de histórias: tradição, poéticas e interfaces. São Paulo: Edições Sesc São Paulo, 2015. - 544pp.

MANZINI, Ezio. Design para inovação social e sustentabilidade: comunidades criativas, 
organizações colaborativas e novas redes projetuais. Cadernos do Grupo de Altos Estudos; V.1. Rio de Janeiro: E-papers, 2008.

PEREIRA, C. C. M. Mitos da Cultura Africana: elementos de informação e preservação da memória na Comunidade Quilombola Alcantarense de Itamatatiua. Dissertação (Mestrado em Ciências da Informação). Universidade Federal da Paraíba. Centro de Ciências Sociais Aplicadas. João Pessoa, $2011.127 \mathrm{f}$.

PORTAS, N. Design: política e formação in Design em aberto: uma antologia. Centro Português de Design, 1993.

REIS, M. das G. O. Filhos da Santa, terras de negro numa arqueologia quilombola: as dinâmicas de um território chamado Itamatatiua. Dissertação. Mestrado em Arqueologia Pré-Histórica e Arte Rupestre. Instituto Politécnico de Tomar. Universidade de Trás-os-Montes e Alto Douro. Departamento de Geologia da UTAD - Departamento de Território, Arqueologia e Patrimônio do IPT. 2010. 190.f.

SILVA, CARINA .S. Abordagem Sistêmica com Foco na Gestão de Design Sustentável: o caso nuovo design. Dissertação (mestrado). Universidade Federal de Santa Catarina. Programa de Pósgraduação em Design e Expressão Gráfica. Florianópolis, SC, 2012. 147 p.

TODARO, M.A. Vovó vai à escola: a velhice como tema transversal no ensino fundamental. Campinas. SP: Papirus, 2009.

VARINE, H. As Raízes do Futuro: O Patrimônio a Serviço do Desenvolvimento Local. Porto Alegre: Medianiz, 2013. 256 p. Tradução de: Maria de Lourdes Parreiras Hortas.

SANTANA, F. A arquitetura da informação e seu propósito. SITE COLETIVO UX, 2017. Disponível em: https://coletivoux.com/arquitetura-de-informação-e-o-seu-propósito-29cd278ebdfe. Acesso em: Março, 2018. 